Araştırma Makalesi / Research Paper

\title{
Radyal Akı Yönlendirmeli Sabit Mıknatısıı Fırçasız DA Motorun Oluk-Kutup Sayısı Değişiminin Manyetik Akı Yoğunluğu Üzerindeki Etkisinin Belirlenmesi
}

\author{
Asım Gökhan YETGIN (D) 1 \\ ${ }^{1}$ Burdur Mehmet Akif Ersoy Üniversitesi, Mühendislik Mimarlık Fakültesi, Burdur \\ Geliş Tarihi (Received): 20.06.2020, Kabul Tarihi (Accepted): 21.08.2020 \\ $\square$ Sorumlu Yazar (Corresponding author ${ }^{*}$ ): agyetgin@mehmetakif.edu.tr \\ (C) +902482132778 且 +902482132704
}

\section{ÖZ}

Sabit mıknatısı fırçasız doğru akım makinaları (SMFDAM) son yıllarda birçok uygulamada kullanılmaya başlamıştır. Farklı yapısal özellikleri sayesinde evsel uygulamalardan elektrikli araçlara kadar kullanım alanı artmaktadır. Motorun tasarım sürecinde genel olarak iç veya dış rotorlu tasarımlar kullanılmakla birlikte, yüzey mıknatıslı, iç yüzey mıknatıslı veya gömülü mıknatısı gibi farklı alternatif tasarımlar da gerçekleştirilmektedir. Bu çalışmada $1,5 \mathrm{~kW}$ gücünde bir SMFDA motorun tasarım modellemesi gerçekleştirilmiş ve farklı stator oluk sayıları ile farklı kutup sayılarının motorun değişik noktalarındaki manyetik akı yoğunluğu değişimlerini nasıl etkilediği incelenmiştir. Manyetik analiz sonuçları RMxprt programından elde edilmiştir. Stator diş ve boyunduruk kısımları, hava aralığı kısmı, rotor boyunduruk kısmı ve kutuplardaki manyetik akı yoğunluğu değişimleri analiz edilmiştir. En uygun oluk-kutup sayısı değerleri tespit edilmiştir.

Anahtar Kelimeler: Manyetik analiz, oluk-kutup sayısı kombinasyonu, SMFDAM

\section{Determination of the Effect of the Slot-Pole Number Change of the Radial- Flux Permanent Magnet Brushless DC Motor on the Magnetic Flux Density}

\begin{abstract}
Permanent magnet brushless direct current machines (PMBLDCM) have been used in many applications in recent years. Thanks to its different structural features, its usage area increases from domestic applications to electric vehicles. In the design process of the motor, although designs with inner or outer rotors are generally used, different alternative designs such as surface magnets, inner surface magnets or embedded magnets are also realized. In this study, design modeling of a $1.5 \mathrm{~kW}$ PMBLDC motor was performed and how different stator slot numbers and different pole numbers affect the magnetic flux density changes at different points of the motor were investigated. Magnetic analysis results were obtained from RMxprt program. Magnetic flux density changes of in the stator tooth and yoke parts, in the air gap part, rotor yoke part and in the poles were analyzed. The most appropriate slot-pole number values were determined.
\end{abstract}

Keywords: Magnetic analysis, number of slot-pole combination, PMBLDCM

\section{GiRiş}

Elektrik motorları, elektrik enerjisini manyetik enerji ile mekanik enerjiye dönüştüren bir tür elektrikli makinedir.
Çeşitli ev ve endüstriyel uygulamalarda yaygın olarak kullanılmaktadır (Wu ve Chen, 2015). Endüstride, çeşitli güç ve ebatlarda, farklı konstrüksiyonlara sahip birçok 
elektrik makinası mevcut olup, bunlardan en yaygın olarak kullanılanı ise asenkron motorlardır. Fakat son yıllarda sabit mıknatıslı fırçasız doğru akım motorları ön plana çıkmaya başlamıştır. Yüksek verim, güvenilir çaıışma ortamı, daha az bakım gereksinimi, sessiz çaIışma, kolay soğutma, uzun ömür ve kolay kontrol edilebilme (Bayraktar, 2014), hafiflik, düşük gürültü ve titreşim (Wu ve Lin, 2012) gibi özellikleri sayesinde SMFDAM'ların kullanımı gün geçtikçe artmaktadır. Bu motorlar özellikle otomotiv sektörü, uzay ve bilgisayar teknolojileri, tıp elektroniği, askeri alanlar, robotik uygulamalar, ev ürünleri (Bayraktar, 2014) ve CNC freze tezgâhları gibi yüksek hızlı uygulamalarda da sıkça kullanımaktadır (Waghmare ve ark., 2016).

SMFDAM tasarımı zaman alıcı ve karmaşık birçok işlem gerektirmektedir. Tasarım sürecinde motora ait birçok parametre göz önüne alınmalı ve istenilen moment, akım, verim vb. kritik değerlerin sürekli olarak kontrolü sağlanmalıdır. Tasarım sonucunda istenilen hedeflere ulaşılamaması durumunda, iteratif olarak hesaplamalar tekrar yapılmalıdır. SMFDAM tasarım sürecinde ana boyutlar, stator ve rotor tasarımı, mıknatıs karakteristikleri ve geometrisi, sargı yapısı vb. noktalar önem arz etmektedir. Motorun tasarım sürecinde performansı doğrudan veya dolaylı yolla etkileyen birçok kritik parametre mevcuttur. Bunlardan birisi de oluk-kutup sayısı oranıdır. SMFDAM' un performansını artırmaya yönelik çalışmalar devam etmekle birlikte oluk-kutup sayısı kombinasyonu ile ilgili yapılmış çalışmalarda en dikkat edici husus, motorun performansını artıracak şekilde hem oluk hem de kutup sayısının değiştirilmesine dayanan çalışmalar olduğu görülmüştür.

Çabuk ve ark. (2017) çalışmalarında, 2.5 kW gücündeki bir FDAM'un oluk-kutup sayısı kombinasyonunun motor performansına etkisini sonlu elamanlar yöntemi kullanarak analiz etmişlerdir. Çalışmada 24/18, 24/20, 36/24, $36 / 28$ ve $36 / 30$ oluk-kutup sayısı kombinasyonlarını kullanmışlardır. Ocak (2018) çalışmasında 6/4, 12/4 ve $15 / 4$ oluk-kutup sayısı kombinasyonuna sahip motorun salınım momenti, verim ve malzeme maliyeti açısından değerlendirmesini yapmıştır. Ayrıca her üç model için nominal moment ve akı yoğunluklarını da incelemiştir. Jafarishiadeh ve ark., (2016), SMFDAM'un oluk-kutup sayısı kombinasyonları 6/4,6/8,12/10,12/14, 18/16 ve $18 / 20$ olacak şekilde modellemeler yapmışlardır. Modellere ait endüktans, salınım momenti ve elektromotor kuvvet değişimlerini analiz etmişlerdir. Aslan ve ark., (2011) çalışmalarında farklı oluk-kutup sayısı kombinasyonlarının sargı faktörü üzerindeki etkisini incelemişlerdir. Sargı faktörlerinin değişimine bağlı olarak motorun performans analizlerini elde etmişlerdir (Aslan ve ark., 2011). Jafarboland ve Mousavi (2018) çalışmalarında $33 / 34$ ve $33 / 36$ oluk-kutup sayısı kombinasyonuna sahip bir SMFDAM' da, dengesiz manyetik kuvvetlerin değişimini sonlu elemanlar yöntemini kullanarak incelemişlerdir. Dusane (2016) çalışmasında dıştan rotorlu bir SMFDAM' un $24 / 16,36 / 18$, 48/22 ve $72 / 28$ oluk-kutup sayılarına sahip 4 farklı motor modelinin RMxprt ve 3-D modellerini oluşturup performans çıktılarını karşılaştırmıştır.

Bu çalışmada SMFDAM' un stator kısmında 18-24-30 ve 36 oluk sayısına sahip bir motor modeli oluşturulmuştur. Oluşturulan her bir stator oluk sayısı için 8 ile 34 arasında değişen kutup sayıları kullanılarak 48 adet farklı oluk-kutup sayısına sahip motor modeli analiz edilmiştir. Analizler için RMxprt programı kullanılmıştır. Motorun hava aralığı, stator boyunduruk, stator diş, rotor boyunduruk ve mıknatıs kısımlarındaki manyetik akı yoğunluğu değişimleri verilmiştir.

\section{Sürekli Mıknatısıı Fırçasızda Motor Çeşitleri}

SMFDAM'lar genel olarak üç grupta toplanabilir. Bunlar iç rotorlu, dış rotorlu ve disk tipi motorlardır. Her bir tasarımın kendine göre avantaj ve dezavantajları mevcuttur.

\section{Dış Rotorlu SMFDAM}

Rotor kısmı stator sargısının dışında olup mıknatıslar bu yuvarlağın içerisine yerleştirilir. İç kısımda bulunan statorda endüvi sargıları, dış kısımda ise sabit mıknatısların bulunduğu rotor dönmektedir. Bu tasarım savrulma durumuna karşı rotorun oldukça dayanıklıdır ve diğer çeşitlerin aksine tek rulman ve yatak kullanılması maliyeti düşürmektedir. Ayrıca yüksek eylemsizliğe sahip olmaları nedeniyle, mevcut hız değerlerini, yükün ani değişimlerinde bile muhafaza ederler. Dezavantajı ise rotorun dışta olmasından dolayı yüksek bir kütleye sahip olması, mıknatısların rotora yerleştirilmesi esnasında bir denge sorunu oluşturabilmektedir (Bayraktar, 2014).

\section{Disk Tipi SMFDAM}

Çelikten yapılan ve iki yüzeyinden birisine mıknatıs yerleştirilen disk şeklindeki rotora sahiptir. Rotor mıknatıslarına karşılık olarak statorda da uyarma sargıları mevcuttur. Düşük hız uygulamalarında, kapalı çevrim kontrolü ve hız geri beslemesine sahip bir sistem kullanılarak çok yumuşak bir performans elde edilebilir. Hız değeri $1000 \mathrm{~d} / \mathrm{d}$ üzerine çıktığında, yapısındaki rotor ve stator disk çeliklerinde ısınma meydana gelmektedir (Bayraktar, 2014). 


\section{İç Rotorlu SMFDAM}

İç rotorlu SMFDA motorlarında hareketli ve mıknatısları taşıyan kısım rotor, motorun iç bölgesinde, duran ve sargıları taşıyan kısım olan stator dış bölgede bulunur. Yüksek hız, yüksek güç ve yüksek moment gerektiren uygulamalarda tercih edilmektedir. Yüksek hızlarda mıknatıs- ları ekstra bağlantı elemanları ve bilezikler ile rotora sabitleme intiyacının ortaya çıkması üretim maliyetlerini arttırmaktadır (Çabuk, 2016).

Her üç motora ait stator ve rotor yapıları Şekil 1' de verilmiştir (Çabuk, 2016).

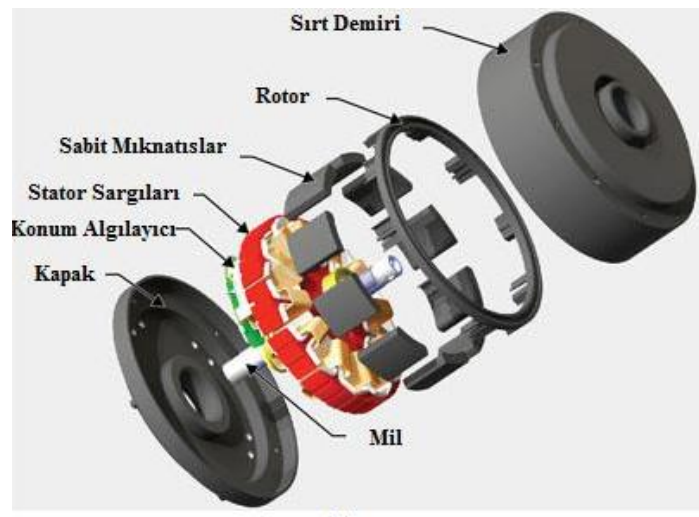

(a)

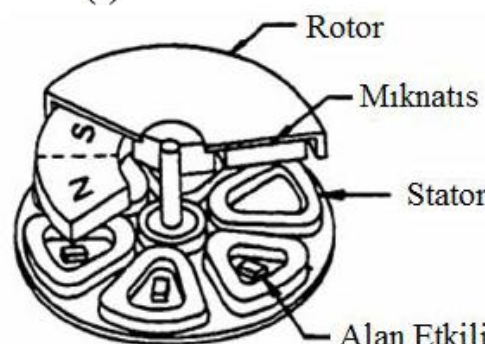

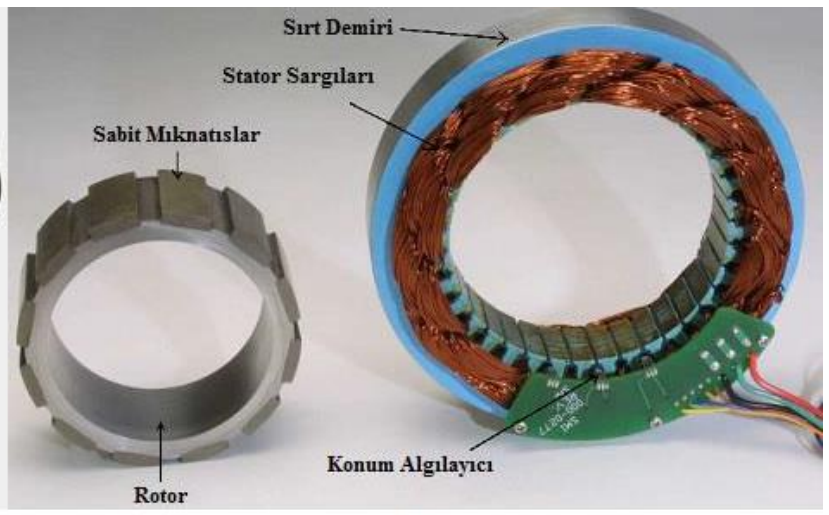

(b)

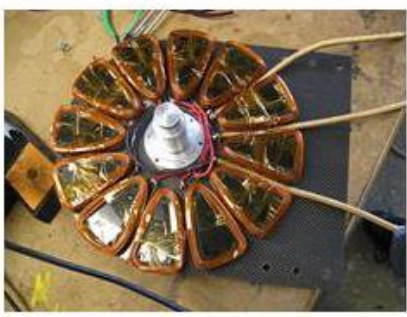

(c)

Şekil 1. a) Dış rotorlu, b) İç rotorlu, c) Disk tipi

\section{İç rotorlu SMFDAM çeşitleri}

İç rotorlu SMFDAM'ların rotor yapıları mıknatısların yerleştirilmesine bağlı olarak, yüzey mıknatıslı, iç yüzey mıknatıslı ve gömülü mıknatıslı olmak üzere üç alt grupta toplanabilir. Her bir yapı için farklı birkaç tasarım seçeneği olabilir, bunlardan bazıları Şekil 2' de verilmiştir. Yüzey mıknatıslı motorlar çok basit bir yapıya, düşük üretim maliyetine ve düşük atalet momentine sahip olmaları avantajları arasında yer alırken, mekanik yönden dayanımının zayıf olması, rotor imalatının zor olması ve hava aralığı akı harmoniklerine maruz kalması dezavantajlarıdır (Sahin, 2010). 

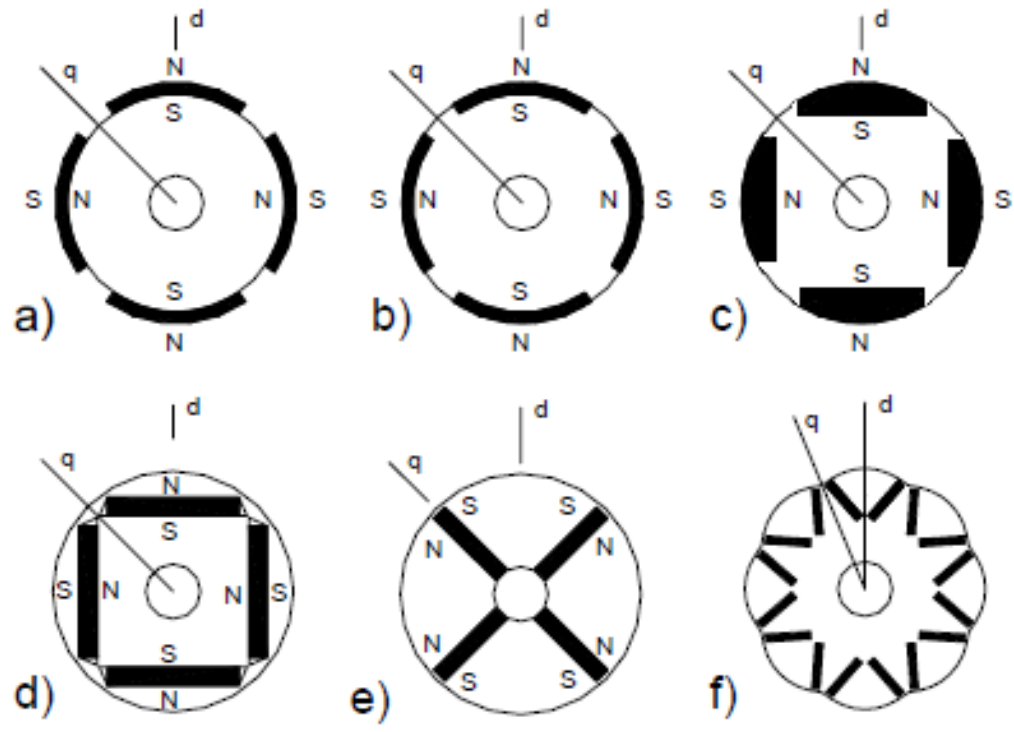

Şekil 2. a) Yüzey mıknatıslı, b,c) İç yüzey mıknatısıı, d,e,f) Gömülü mıknatısı

\section{Oluk-Kutup Sayısı Kombinasyonları ve Motor Özel- likleri}

SMFDAM'lardaki oluk ve kutup sayısı arasındaki ilişki motorun performansını belirlemede kritik parametrelerden birisidir. Seri üretim motorların en iyi performansı sunan oluk/kutup sayısı konfigürasyonlarına sahip olduğu düşünülse de, bilgisayar destekli çeşitli analizler bunun her zaman böyle olmadığını göstermektedir. Örneğin, çoğu 4 kutuplu SMFDAM 12 stator oluklu olarak üretilmektedir. Bununla birlikte, bu tip tasarım çok yüksek bir salınım momentine ve yüksek bakır kayıplarına sahiptir. Ek olarak, sarım ve işçilik maliyeti fazladır. Daha düşük bir salınım momenti ve maliyet hedefi için 4 kutuplu/6 oluklu konfigürasyon tercih edilebilir. Düşük salınım momenti ve sinüzoidal bir elektromotor kuvvetine sahip bir motor isteniyorsa, yukarıda belirtilen diğer alternatiflere kıyasla 4 kutuplu/15 oluklu konfigürasyon en iyi seçim olacaktır (Ocak, 2018).

Hendershot (1990) çalışmasında, çoğu 8 kutuplu motorların 24 oluklu yapı ile kullanıldığını, fakat 18 oluklu motorun daha iyi performans verdiğini ifade etmiştir. Yine 8 kutuplu 9 oluklu motorun çok düşük salınım momentine sahip olduğunu ve her iki 8 kutuplu motor tasarımının düşük hızlarda nerdeyse mükemmel bir sinüzoidal moment ürettiklerini belirtmiştir. Jafarishiadeh ve Amini (2017) çalışmalarında 10 kutuplu, stator oluk sayıları 12 ve 15 olan iki SMFDAM' un performans analizlerini yapmışlardır. 12 oluklu motorun ortalama moment değerinin 15 oluklu motora göre daha yüksek elde edildiğini belirtmiştir. Fakat 15 oluklu motorun moment salınımının daha düşük olduğunu, bu durumun düşük titreşim ve gürültü gerektiren uygulamalarda tercih edilebileceğini ifade etmiştir (Jafarishiadeh ve Amini, 2017).

Bu çalışmada kullanılan SMFDAM' a ait oluk/kutup sayısı kombinasyonları Tablo 1' de verilmiştir. Oluk ve kutup sayıları aynı olmayacak şekilde, motorlarda en çok kullanılan stator oluk sayıları olan $18,24,30$ ve 36 oluk seçilmiş, kutup sayıları ise 8-34 arasında değiştirilmiştir. Kutup sayısının motor performansı üzerindeki etkisinin ve farklı oluk sayılarına göre en uygun oluk/kutup sayısının belirlenebilmesi amacıyla kutup sayısı 8-34 arasında seçilmiştir. Tablo 1' de verilen " $x$ " simgesi, analizi yapılan motor modellerini ifade etmektedir.

Tablo 1. Oluk/Kutup sayısı kombinasyonları

\begin{tabular}{ccccccccccccccc}
\hline Kutup S. & 8 & 10 & 12 & 14 & 16 & 18 & 20 & 22 & 24 & 26 & 28 & 30 & 32 & 34 \\
\hline 18 & $\mathrm{x}$ & $\mathrm{x}$ & $\mathrm{x}$ & $\mathrm{x}$ & $\mathrm{x}$ & & $\mathrm{x}$ & $\mathrm{x}$ & $\mathrm{x}$ & & & & & \\
$\mathbf{2 4}$ & $\mathrm{x}$ & $\mathrm{x}$ & $\mathrm{x}$ & $\mathrm{x}$ & $\mathrm{x}$ & $\mathrm{x}$ & $\mathrm{x}$ & $\mathrm{x}$ & & $\mathrm{x}$ & $\mathrm{x}$ & $\mathrm{x}$ & $\mathrm{x}$ & $\mathrm{x}$ \\
$\mathbf{3 0}$ & $\mathrm{x}$ & $\mathrm{x}$ & $\mathrm{x}$ & $\mathrm{x}$ & $\mathrm{x}$ & $\mathrm{x}$ & $\mathrm{x}$ & $\mathrm{x}$ & $\mathrm{x}$ & $\mathrm{x}$ & $\mathrm{x}$ & & $\mathrm{x}$ & $\mathrm{x}$ \\
$\mathbf{3 6}$ & $\mathrm{x}$ & $\mathrm{x}$ & $\mathrm{x}$ & $\mathrm{x}$ & $\mathrm{x}$ & $\mathrm{x}$ & $\mathrm{x}$ & $\mathrm{x}$ & $\mathrm{x}$ & $\mathrm{x}$ & $\mathrm{x}$ & $\mathrm{x}$ & $\mathrm{x}$ & $\mathrm{x}$ \\
\hline
\end{tabular}


Çalışmada kullanılan SMFDAM' u 1,5 kW, 48 V, 500 d/d, iç rotorlu ve yüzey mıknatıslıdır. Stator ve rotorda kullanılan malzeme M19-24G, kutuplarda kullanılan mıknatıs
NdFe35'dir. Motora ait diğer büyüklükler Tablo 2' de verilmiştir.

Tablo 2. Motora ait diğer parametreler (Dusane, 2016)

\begin{tabular}{lcc}
\hline \multicolumn{1}{c}{ Motor Parametresi } & Simge & Değer \\
\hline Stator dış çap & $D_{s d}$ & $210 \mathrm{~mm}$ \\
Stator iç çap & $D_{s i}$ & $110 \mathrm{~mm}$ \\
Paket boyu & $L$ & $50 \mathrm{~mm}$ \\
Sarım şekli & $d$ & Çift katmanlı-tam kalıp \\
Iletken kesiti & $d .369 \mathrm{~mm}$ \\
Rotor dış çap & $D_{r d}$ & $108 \mathrm{~mm}$ \\
Rotor iç çap & $D_{\text {mil }}$ & $40 \mathrm{~mm}$ \\
Mıknatıs kalınlığı & $h$ & $4 \mathrm{~mm}$ \\
Mıknatıs ara uzunluğu & $d$ & 0.9 \\
Oluk üst genişliği & $B_{s 1}$ & $6 \mathrm{~mm}$ \\
Oluk alt genişliği & $B_{s 2}$ & $12 \mathrm{~mm}$ \\
Oluk ağız açıklığı & $B_{s 0}$ & $2 \mathrm{~mm}$ \\
Oluk yüksekliği & $H_{s 2}$ & $30 \mathrm{~mm}$ \\
Kama yüksekliği & $H_{s 0}$ & $2 \mathrm{~mm}$ \\
Kama genişliği & $H_{s 1}$ & $1 \mathrm{~mm}$ \\
\hline
\end{tabular}

\section{YÖNTEM}

Sonlu elemanlar yöntemi, karmaşık manyetik devre geometrisine ve doğrusal olmayan manyetik malzemelere sahip motorların manyetik vektör potansiyel değerlerini elde etmek için uygun bir şekilde kullanılabilir. Analizler sonucu elde edilen bu vektör potansiyel değerleri manyetik alan dağılımı, moment, kaçak akı vb. değerleri elde etmek için kullanılır (Afjei ve ark., 2007). Bununla birlikte üç boyutlu analizler yapılarak daha net sonuçların elde edilmesi mümkündür.
Bu çalışmada SMFDAM' un analizi için Maxwell-RMxprt programı kullanılmıştır (URL-1). Programda RMxprt üzerinden her bir motor modeli için değerler elde edilmiştir. RMxprt modelinde motorun güç, gerilim vb. genel parametreleri, dış-iç çap, uzunluk vb. ebat ölçüleri, oluklara ait değerler, malzeme özellikleri, sargı yapısı gibi parametreler girilerek analizler gerçekleştirilmiştir. Motor modellerinde stator oluk sayısı ve kutup sayısı dışındaki diğer parametreler sabit tutulmuştur. Stator oluk sayısı 36, kutup sayısı 24 olan motor modelinin kesit görüntüsü, stator oluk yapısı ve kutup yapısı Şekil 3' de verilmiştir.

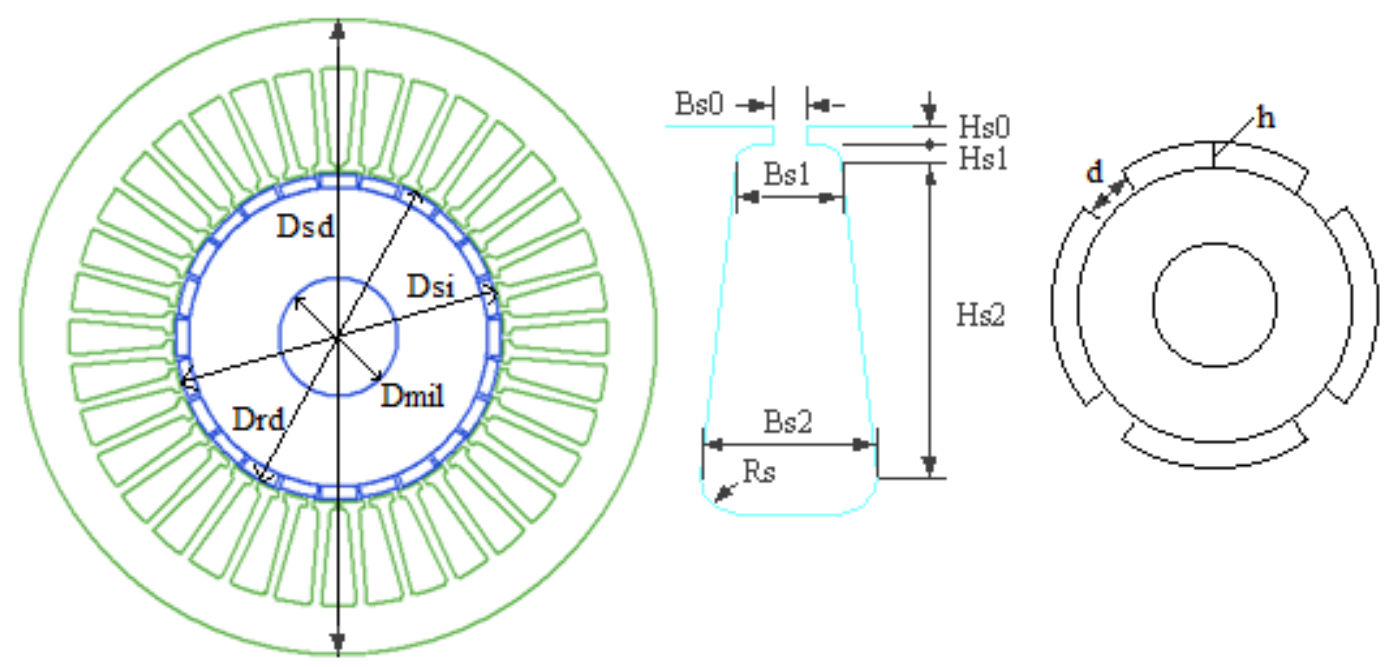

Şekil 3. 36/24 motor modeli, stator oluk ve kutup yapıları 
Stator ve rotor nüvesinde kullanılan M19-24G malzemesine ait B-H eğrisi ve kayıp güç eğrisi Şekil 4' de verilmiştir. Manyetik analizlerde doyum noktalarının görülebilmesi açısından B-H eğrisi tanımlanmıştır.

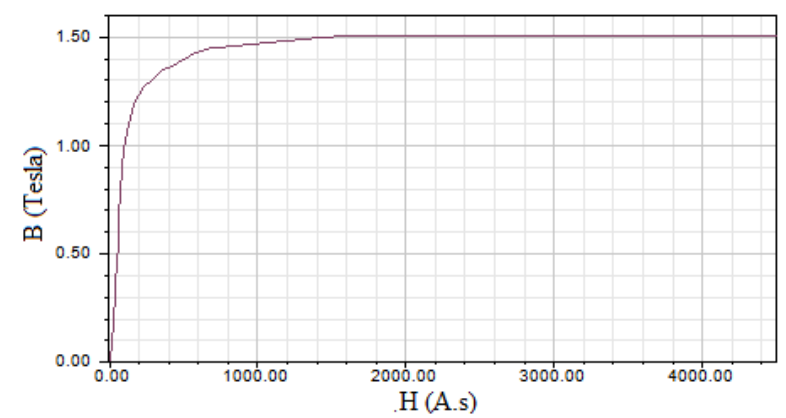

Tasarlanan motorun mıknatısları için programın kendi kütüphanesinde bulunan NdFe35 mıknatıs yapısı seçilmiştir. Seçilen mıknatıs özellikleri Tablo 3' de verilmiştir. Bu mıknatıs güçlü çekim gücüne sahip nadir element adı verilen Neodium Iron Boron ( $\mathrm{NdFeB}$ ) türü mıknatıslardandır (Ayçiçek ve ark., 2012).

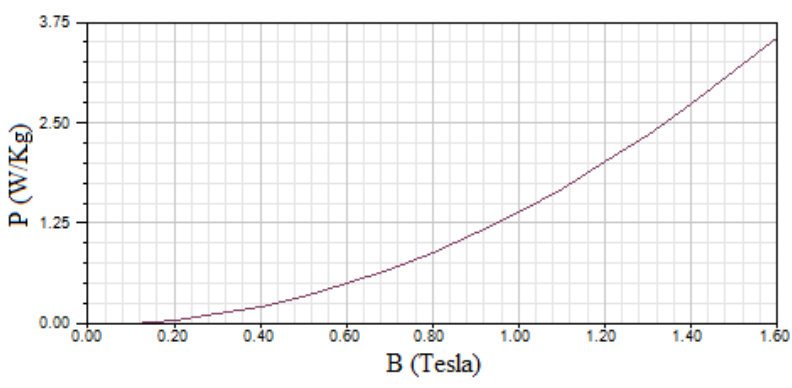

Şekil 4. M19-24G malzemesine ait B-H eğrisi ve kayıp güç eğrisi (Zhang ve ark., 2011)

Tablo 3. NdFe35 mıknatıs yapısının özellikleri

\begin{tabular}{ll}
\hline \multicolumn{1}{c}{ Parametre } & \multicolumn{1}{c}{ Değer } \\
\hline Geçirgenlik & 1.0997785406 \\
İletkenlik & $6.25 \mathrm{e}+005$ siemens/metre \\
Artık mıknatıslanma $\left(H_{c}\right)$ & $-8.9 \mathrm{e}+005$ amper/metre \\
Mıknatıs akı yoğunluğu $\left(B_{r}\right)$ & 1.23 Tesla \\
\hline
\end{tabular}

\section{ARAŞTIRMA BULGULARI}

$\mathrm{Bu}$ kısımda modellemesi yapılan motorların manyetik analizleri ve motorun saturasyona girip girmediğinin belirlendiği akı yoğunluğu değerlerinin nasıl değiştiği verilmiştir. Stator boyunduruk kısmındaki, stator dişlerindeki, hava aralığındaki, rotor boyunduruk kısmındaki ve mıknatıslardaki akı yoğunluğu değişimleri gösterilmiştir.

Modellemesi yapılan sabit mıknatıslı fırçasız doğru akım motorun stator boyunduruk akı yoğunluğu değerleri oluk-kutup sayısı değişimine göre Şekil 5' de verilmiştir. Şekil incelendiğinde düşük kutup sayılarında akı yoğunluğu değerlerinin yüksek elde edildiği, kutup sayısının artması ile birlikte akı yoğunluğu değerlerinin azaldığı görülmektedir. Oluk sayısının değişimine göre bakıldığında, oluk sayısı arttıkça stator boyunduruk akı yoğunluğu değerinin çok az miktarda azaldığı görülmektedir.

Şekil 6' da kutup sayısına bağlı olarak stator dişlerindeki akı yoğunluğu değişimleri verilmiştir.

Şekil 6 incelendiğinde kutup sayısının artması ile birlikte stator dişlerindeki akı yoğunluğu değerlerinin azaldığı görülmektedir. Stator oluk sayısının 18' den 36' ya doğru artması ile birlikte, stator diş genişliği değerinin azalmasına bağlı olarak stator dişlerindeki akı yoğunluğu değerlerinin de arttığı görülmektedir.

Şekil 7' de hava aralığındaki akı yoğunluğu değişimleri verilmiştir. 


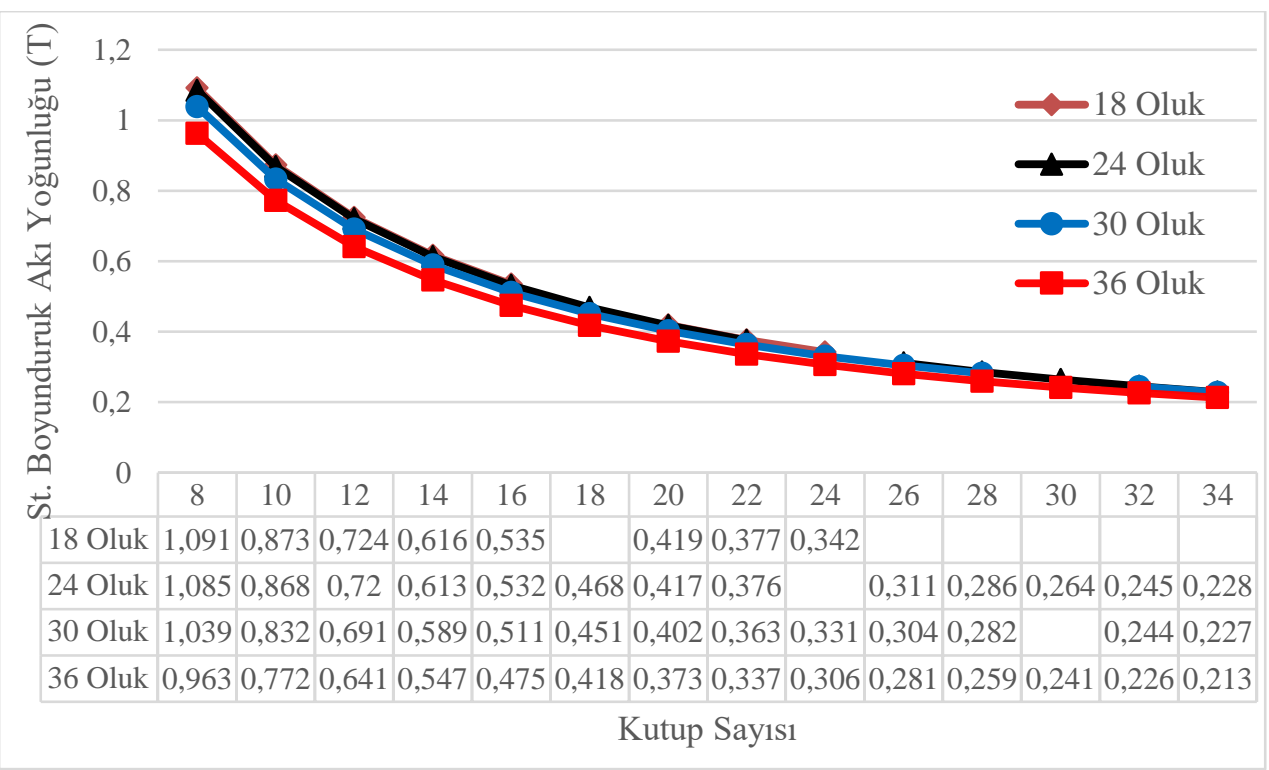

Şekil 5. Stator boyunduruk akı yoğunluğu değişimi

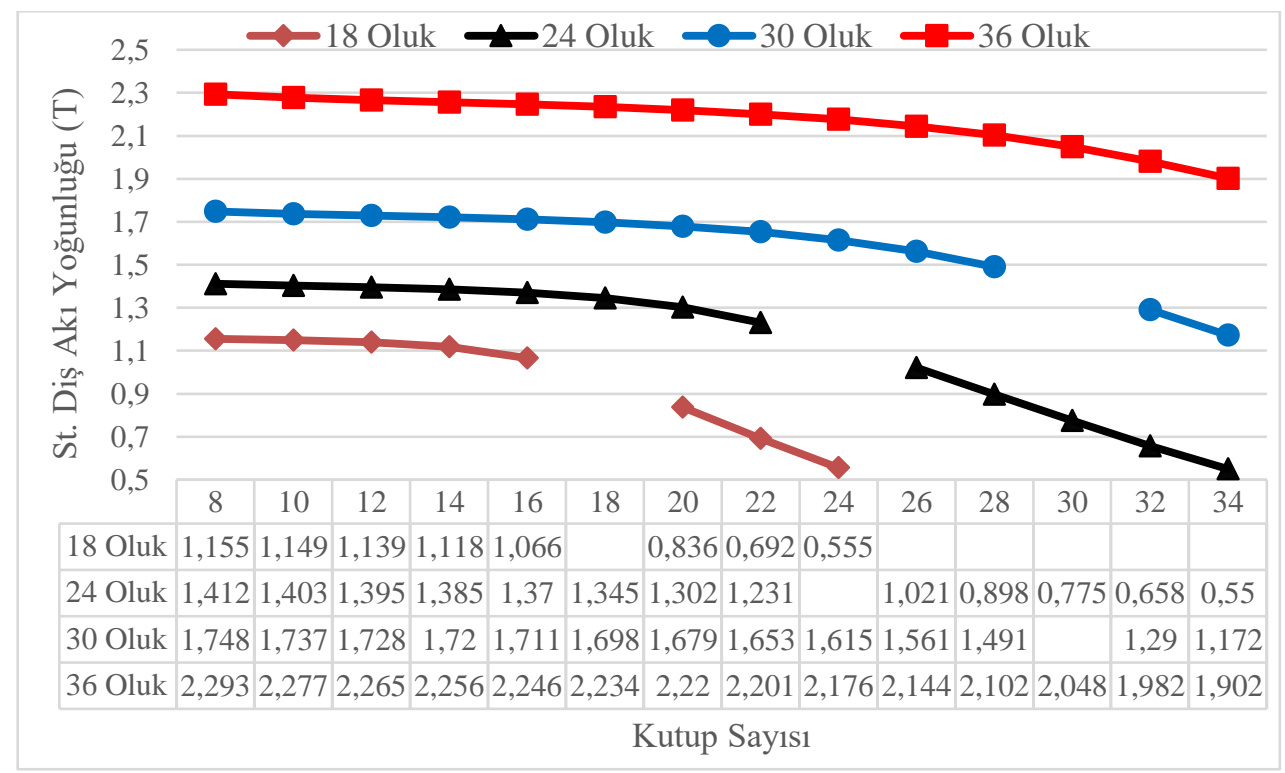

Şekil 6. Stator diş akı yoğunluğu değişimi 


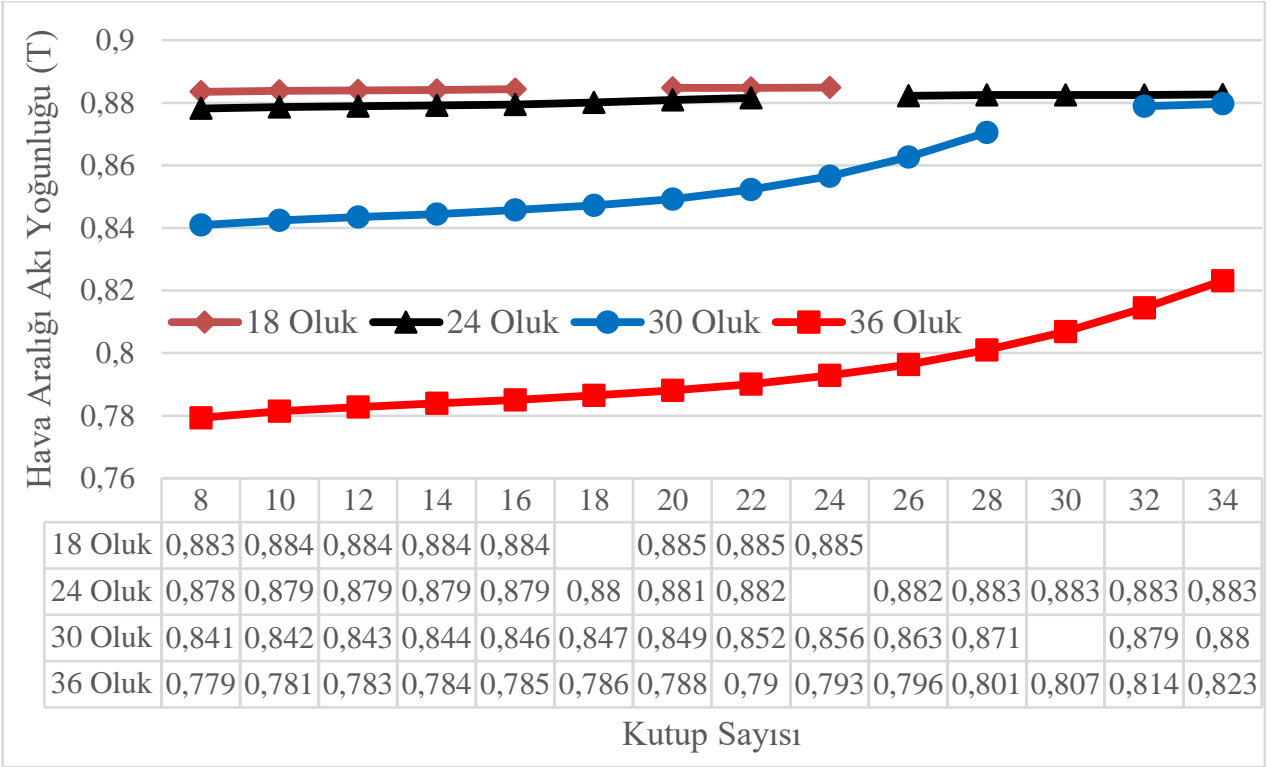

Şekil 7. Hava aralığı akı yoğunluğu değişimi

Şekil 7 incelendiğinde kutup sayısının artması ile birlikte hava aralığı akı yoğunluğu değerinin artma eğiliminde olduğu görülmektedir. Dişlerdeki akı yoğunluğu değişiminin tersi bir şekilde oluk sayısının artması ile birlikte hava aralığı akı yoğunluğu değişimi azalmaktadır.
Şekil 8' de mıknatıslar üzerindeki manyetik akı yoğunluğu değişimleri verilmiştir.

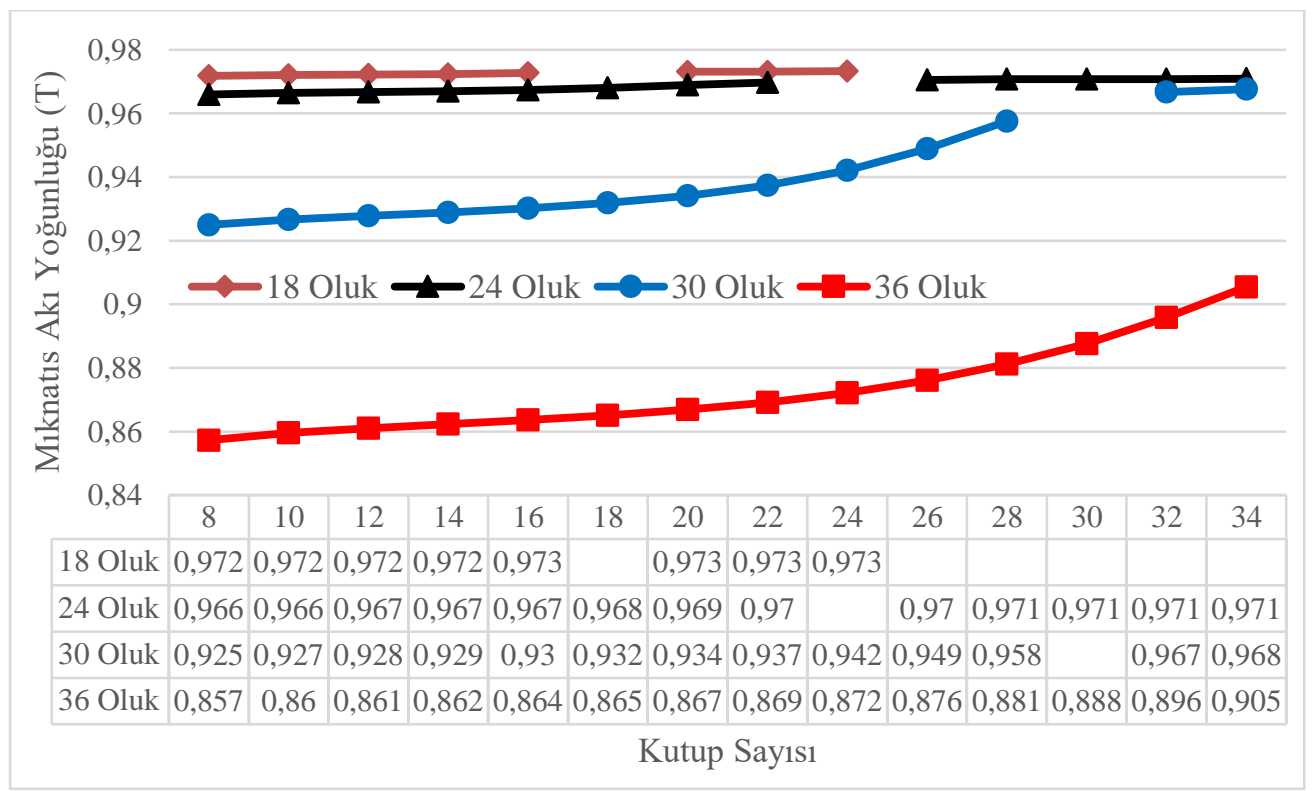

Şekil 8. Mıknatıslardaki akı yoğunluğu değişimi

Şekil 8 incelendiğinde kutup sayısının artması ile birlikte kutuplarda meydana gelen manyetik akı yoğunluğu değerlerinin artış gösterdiği anlaşılmaktadır. Stator oluk sayısının azalması kutuplarda meydana gelen akı değerlerinde bir artış ile sonuçlanmıştır. Kutuplardaki manyetik akı yoğunluğu değerini etkileyen diğer bir faktör de mıknatısın kalınlığıdır. Bu çalışmada mıknatıs kalınlığı bütün motor modellerinde sabit alındığı için direkt olarak kutup sayısının etkisi görülebilmektedir. 
Şekil 9' da motorun rotor boyunduruk kısmında meydana gelen manyetik akı yoğunluğu değişimleri verilmiştir.

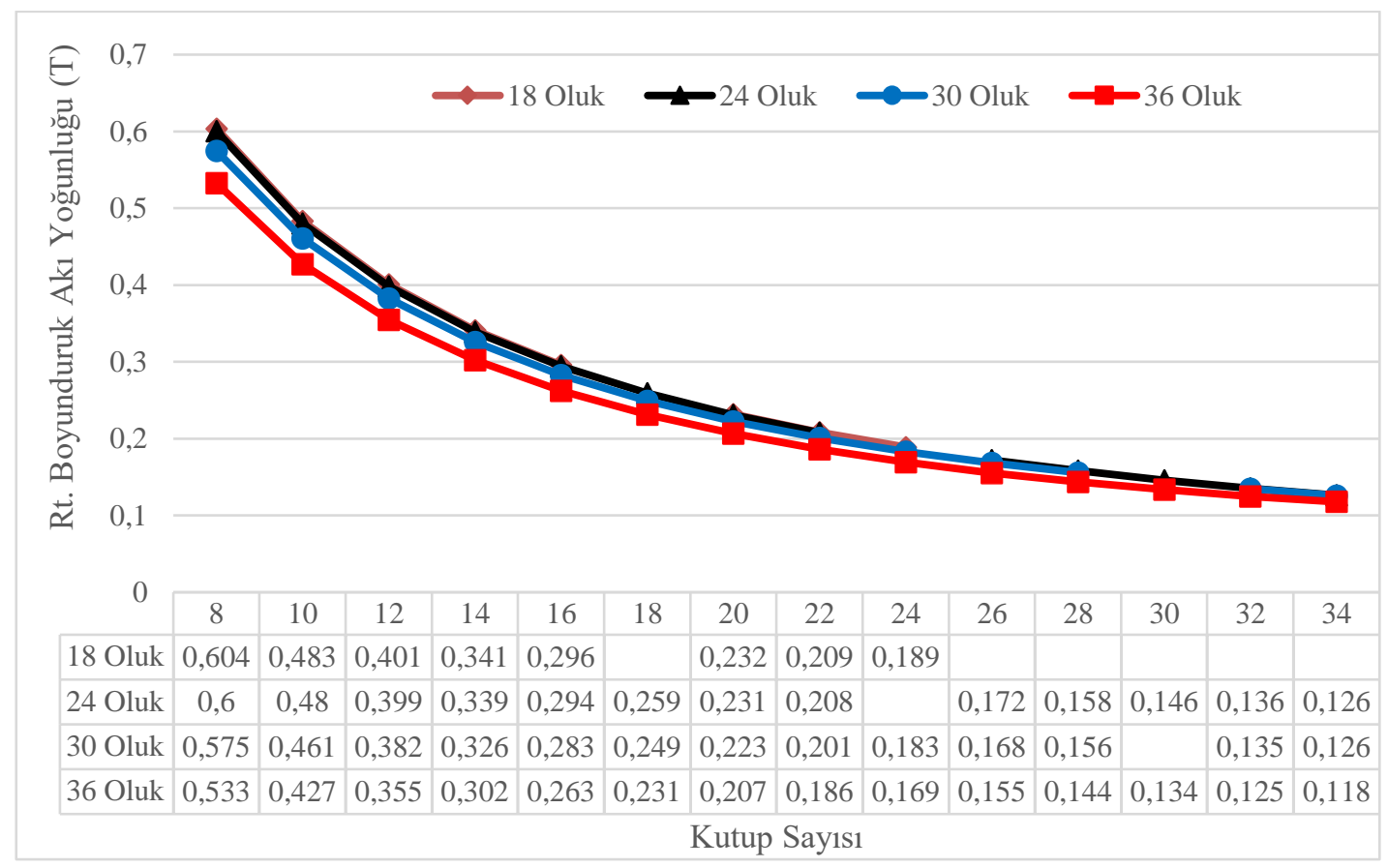

Şekil 9. Rotor boyunduruk akı yoğunluğu değişimi

Şekil 9 incelendiğinde manyetik akı yoğunluğu değişiminin stator boyunduruk akı yoğunluğu değişimi ile benzerlik gösterdiği, rotor boyunduruk yüksekliğinin fazla olmasından dolayı akı yoğunluğu değerlerinin daha düşük elde edildiği görülmektedir. Yine benzer şekilde kutup sayısının artması ile akı yoğunluğu değerlerinde biz azalma meydana gelmiştir. Stator oluk sayısının ise çok fazla bir etkisinin olmadığı görülmektedir.

\section{SONUÇLAR}

Bu çalışmada sabit mıknatıslı fırçasız doğru akım motorunun RMxprt programında tasarımı gerçekleştirilmiş ve motorun çeşitli bölgelerindeki manyetik akı yoğunluğu dağılımları analiz edilmiştir. Elde edilen sonuçlar şu şekildedir.

- Stator boyunduruk akı yoğunluğu değerlerinin kutup sayısı değerinin artması ile birlikte hızlı bir şekilde azaldığı, oluk sayısının fazla bir etkisinin olmadığı tespit edilmiştir. Maksimum ve minimum stator boyunduruk akı yoğunlukları arasında \% 80.49 oranında bir fark olduğu görülmektedir.

- Stator diş akı yoğunluğu değerlerinde ise oluk sayısının artması, stator dış ve iç çap değerlerinin sabit kalması nedeniyle, diş genişliklerinin azalmasına bağlı olarak arttığı görülmüştür. Kutup sayısının artması ile dişlerdeki akı yoğunluğu değerlerinde azalma ile sonuçlanmıştır.

- Hava aralığı akı yoğunluğu değerlerinin, küçük oluk sayısına sahip modellerde daha fazla elde edildiği, bunun sebebinin ise gerekli olan manyetomotor kuvvetinin elde edilmesi için manyetik akı yoğunluğu değerinin artmasına bağlı olduğu tespit edilmiştir.

- Mıknatıslardaki akı yoğunluğu değerlerinde ise hava aralığındaki değişimlere benzer grafiklerin elde edildiği tespit edilmiştir. Bunun sebebi ise hava aralığındaki akıların direkt olarak mıknatıslara geçmesinden kaynaklanmaktadır.

- Rotor boyunduruk akı yoğunluğu değişiminin stator boyunduruk akı yoğunluğu değişimi ile benzer olduğu görülmüştür. Maksimum rotor boyunduruk akı yoğunluğu $0.604 \mathrm{~T}$ iken minimum değer ise $0.118 \mathrm{~T}$ olarak elde edilmiştir.

Manyetik akı yoğunluğu değişimlerinin tamamı göz önüne alındığında, akı yoğunluğu değerlerinin az olması gerekli olan manyeto motor kuvvetinin sağlanamayacağı anlamına gelmekte ve buda motor performansını olumsuz yönde etkileyecektir. Akı yoğunluğu değerlerinin fazla çıkması durumunda ise, demir kayıplarının manyetik akı yoğunluğunun karesi ile değişmesine bağlı olarak, demir kayıplarının fazla çıkması ile sonuçlanacak olmasından dolayı verimde bir azalma meydana getirecektir. 
Bu sebeple akı yoğunluğu değerlerinin her bir kısım için grafiklerin orta kısımlarında (14-16-18-20 kutup sayısı) olan motor modellerinin uygun olacağı sonucuna varılmıştır.

Bundan sonraki çalışmalarda ise motor modellerinin geçici hal durum analizleri yapılarak akım, moment, vuruntu momenti gibi değişimler ele alınabilir.

\section{KAYNAKLAR}

Afjei, E., Hashemipour, O., Saati, M.A., Nezamabadi, M.M. (2007). A new hybrid brushless dc motor/generator without permanent magnet, IJE Transactions B: Applications 20(1): 77-86.

Aslan, B., Semail, E., Korecki, J., Legranger, J. (2011). Slot/pole combinations choice for concentrated multiphase machines dedicated to mild-hybrid applications. IEEE International Conference on Industrial Applications of Electronics IECON'11, Nov 7-10, 2011, Melbourne, VIC, Australia, Book of Proceedings, 3698-3703p.

Ayçiçek, E., Bekiroğlu, N., Şenol, İ. (2012). Optimization of rotor structure for providing minimum cogging moment by using open slot method in axial flux permanent magnet motors, Journal of Engineering and Natural Sciences 30: 392 401.

Bayraktar, H.C. (2014). Fırçasız doğru akım motorlarının kontrolü. Seminer Tezi, İstanbul Aydın Üniversitesi Fen Bilimleri Enstitüsü, İstanbul, 73.

Çabuk, A.S. (2016). Tekerlek içi fırçasız doğru akım motorlarının en iyi tasarımı için yeni bir yaklaşım. Doktora Tezi, Marmara Üniversitesi Fen Bilimleri Enstitüsü, İstanbul, 135

Cabuk, A.S., Sağlam, S., Üstün, O. (2017). Impact of various slot-pole combinations on an in-wheel bldc motor performance. Istanbul University Journal of Electrical and Electronics Engineering 17(2): 3369-3375.

Dusane, P.M. (2016). Simulation of a brushless dc motor in ansys - maxwell 3d. Master Thesis, Czech Technical University, Czech Republic, 108.

Hendershot, J.R. (1990). Brushless dc motor phase, pole, and slot configurations. Proceedings of 9th International Symposium on Incremental Motion Control Systems and Devices, 1990, 146-159p.
Jafarboland, M., Mousavi, S.M. (2018). Investigation of unbalanced magnetic force in permanent magnet brushless dc machines with diametrically asymmetric winding. Journal of Operation and Automation in Power Engineering 6(2): 255267.

Jafarishiadeh, S., Amini, M. (2017). Design and comparison of axial-flux pm bldc motors for direct drive electric vehicles: conventional or similar slot and pole combination. International Journal of Engineering Innovation \& Research 6(1): 15-20.

Jafarishiadeh, S., Ardebili, M., Marashi, A.N. (2016). Investigation of pole and slot numbers in axial-flux pm bldc motors with single-layer windings for electric vehicles. 24th Iranian Conference on Electrical Engineering (ICEE), May 10-12, 2016, Shiraz, Iran, Book of Proceedings, 1444-1448p.

Ocak, C. (2018). Design and performance comparison of fourpole brushless dc motors with different pole/slot combinations. The International Journal of Energy \& Engineering Sciences 3(3): 69-78.

Sahin, İ. (2010). Measurement of brushless dc motor characteristics and parameters and brushless dc motor design. Master Thesis, Middle East Technical University, Ankara, 219.

URL-1 (2019). Ansys Maxwell 2D Electronic Design Automation Software. 2012. http://www.ansys.com. (Erişim Tarihi: 05/02/2020).

Waghmare, T., Choube, P.R., Dakre, A., Suryawanshi, A.M., Holambe, P. (2016). Design of internal permanent magnet brushless dc motor using ansys. International Journal of Research Publications in Engineering and Technology 2(4): 1-7.

Wu Y.C., Lin, B.W. (2012). Computer-aided design of a brushless dc motor with exterior-rotor configuration. ComputerAided Design and Applications 9(4): 457-469.

Wu, Y.C., Chen, Y.T. (2015). Mitigation of cogging torque for brushless interior permanent-magnet motors. Sharif University of Technology Scientia Iranica Transactions B: Mechanical Engineering 22(6): 2163-2169.

Zhang, Y., Cheng M.C., Pillay, P. (2011). A novel hysteresis core loss model for magnetic laminations IEEE Transactions on Energy Conversion 26(4): 993-999. 